\title{
A DEMOCRACIA DELIBERATIVA E PARTICIPATIVA COMO PRESSUPOSTOS NA CONSTRUÇÃO DE POLÍTICAS PÚBLICAS SOCIOAMBIENTAIS.
}

\author{
DELIBERATIVE AND PARTICIPATORY DEMOCRACY AS \\ ASSUMPTIONS IN THE CONSTRUCTION OF SOCIAL AND \\ ENVIRONMENTAL PUBLIC POLICIES.
}

\section{Ana Carolina Farias Ribeiro ${ }^{1}$ \\ Loiane Prado Verbicaro ${ }^{2}$ \\ Luciana Costa da Fonseca ${ }^{3}$}

\begin{abstract}
RESUMO: $O$ texto discute a importância da participação e da deliberação, especificamente nas questões socioambientais. A busca pela participação qualificada é analisada por meio da interpretação e aplicação das teorias de democracia participativa e deliberativa, trabalhadas por Frank Cunningham, e investiga de que forma essas teorias podem contribuir para efetivação da participação popular na construção de políticas públicas socioambientais, que garantam uma participação qualificada do cidadão. Quanto aos objetivos, a pesquisa aqui apresentada é exploratória, visando proporcionar maior familiaridade com o problema investigado, explicitá-lo e construir hipóteses sobre a relação entre as teorias e as políticas públicas socioambientais. A abordagem é qualitativa e utilizou como procedimento o levantamento bibliográfico sobre o tema. A pesquisa concluiu que as teorias pesquisadas auxiliam e maximizam a participação popular qualificada e contribuem
\end{abstract}

\footnotetext{
${ }^{1}$ Professora de Direito da Universidade da Amazônia, Belém-PA. Mestre em Direito, Políticas Públicas e Desenvolvimento Regional pelo Centro Universitário do Pará. Pesquisadoras do Grupo de Pesquisa Mineração e Desenvolvimento Regional na Amazônia. Currículo Lattes: http://lattes.cnpq.br/9476184863640367. Orcid: https://orcid.org/0000-0002-2531-5012. E-mail: carol fariasribeiro@ hotmail.com.

${ }^{2}$ Professora da Faculdade de Filosofia e do Programa de Mestrado em Filosofia da Universidade Federal do Pará (UFPA), Belém-PA. Integrante da Rede Brasileira de Mulheres Filósofas. Líder do Grupo de Pesquisa: Filosofia Prática: Investigações em Política, Ética e Direito. Currículo Lattes: http://lattes.cnpq.br/4100200759767576. Orcid: https://orcid.org/0000-0002-3259-9906. E-mail: loianeverbicaro@uol.com.br.

${ }_{3}^{3}$ Professora da Universidade Federal do Pará - UFPA e do Centro Universitário do Pará - CESUPA, Belém-PA. Doutora e Mestre em Direito pela Pontifícia Universidade Católica de São Paulo. Especialista em Direito Sanitário pela Universidade de São Paulo - USP. Currículo Lattes: http://lattes.cnpq.br/3383269305393137. Orcid: https://orcid.org/0000-0001-9330-2208. E-mail: lfonseca@ufpa.br.
} 
para o aperfeiçoamento de políticas públicas capazes de solucionar conflitos socioambientais.

Palavras-chave: Conflito Socioambiental; Democracia Participativa; Deliberação; Participação.

ABSTRACT: The text discusses the importance of participation and deliberation, specifically in social and environmental issues. The search for qualified participation is analyzed through the interpretation and application of the theories of participative and deliberative democracy, worked by Frank Cunningham, and investigates how these theories can contribute to the realization of popular participation in the construction of social and environmental public policies that guarantee participation qualified citizen. The research presented here is, in terms of objectives, exploratory, aiming to provide greater familiarity with the problem investigated, explain it and build hypotheses about the relationship between theories and social and environmental public policies. The approach is qualitative and used the bibliographic survey on the topic as a procedure. The research concluded that the researched theories help and maximize qualified popular participation and contribute to the improvement of public policies capable of solving socio-environmental conflicts.

Keywords: Socioenvironmental Conflict; Participatory Democracy; Deliberation; Participation.

SÚMARIO: 1. Introdução; 2. A participação e a informação nas questões ambientais; 3. A contribuição da democracia participativa de Rousseau; 4. A aplicação do participacionismo e da deliberação na maximização do debate socioambiental; 5. Considerações Finais; 6. Referências Finais.

\section{INTRODUÇÃO}

O objetivo desta pesquisa é analisar a aplicação das teorias democráticas participativas e deliberativas no engajamento da população para a construção de políticas públicas socioambientais. A preocupação com o meio ambiente ecologicamente equilibrado é fundamental para a garantia de uma sadia qualidade de vida, visto que nada melhor do que o próprio cidadão para identificar suas necessidades na busca da melhoria de vida.

O indivíduo deve participar da construção e fiscalização de políticas públicas que possam comprometer a conservação dos recursos naturais para as presentes e 
futuras gerações.

Em face dos desafios socioambientais e da busca pelo desenvolvimento sustentável, a Constituição da República Federativa do Brasil - CRFB garante o direito ao meio ambiente ecologicamente equilibrado (Art. 225), elege a proteção do meio ambiente como um princípio da ordem econômica (Art. 170, VI) e regulamenta os princípios da informação e participação popular como direitos fundamentais, essenciais para Estado democrático.

Os princípios da informação e da participação são complementares, na medida em que a participação requer o acesso à informação qualificada, para que haja o efetivo engajamento da comunidade na elaboração e controle de políticas públicas e na solução de conflitos socioambientais. Em resumo, para participar, é preciso estar informado. Os princípios caminham juntos para que se concretize a participação popular.

Todavia, mesmo que a população esteja munida de informações adequadas, pode não ser suficiente para que ocorra a participação efetiva, já que nem sempre existe a cultura de participar e o interesse de contribuir, muitas vezes, não é claramente identificado.

A população precisa ser estimulada a participar do debate de políticas e soluções de conflitos socioambientais, por meio dos instrumentos jurídicos disponíveis, pois é comum a apatia, por isso a necessidade de investigar e estudar esse fenômeno.

As teorias estudadas por Frank Cunningham (2009, s.p.) em “Teorias da Democracia" são importantes para a compreensão dessa problemática, já que estudam formas de como a participação pode ocorrer de forma qualificada, e quais os obstáculos encontrados, podendo auxiliar no avanço da participação popular nas políticas socioambientais.

As principais teorias que serão analisadas neste estudo serão a da democracia participativa, buscando compreender o participacionismo e a da democracia 
deliberativa, como complemento e reforço da primeira. Ambas precisam ser compreendidas juntas para a concretização do ideal da participação.

A pesquisa busca responder ao seguinte problema de pesquisa: de que forma as teorias da democracia participativa e deliberativa poderiam contribuir para uma maximização da participação popular nas questões ambientais?

Quanto aos objetivos, a pesquisa apresentada é exploratória, visando proporcionar maior familiaridade com o problema investigado, explicitá-lo e construir hipóteses sobre a relação entre as teorias e as políticas públicas socioambientais. A abordagem da pesquisa é qualitativa e utilizou como procedimento o levantamento bibliográfico sobre o tema.

O texto está estruturado em três seções principais, além dessa introdução e das considerações finais. A seção 2 tem como objetivo específico analisar a importância dos princípios da informação e participação nas questões socioambientais. A seção 3 tem como objetivo específico apresentar a teoria da democracia participativa de Rousseau e suas principais contribuições para uma participação qualificada, apresentando também críticas e entornos a respeito dela. A seção seguinte e última, tem como objetivo específico analisar a aplicação das teorias da democracia participativa e da democracia deliberativa no debate relacionado à questão socioambiental, especificamente no que diz respeito à participação popular, e como tais teorias poderiam auxiliar na participação qualificada. Por fim, são apresentadas as conclusões.

\section{A PARTICIPAÇÃO E INFORMAÇÃO NAS QUESTÕES AMBIENTAIS}

A Constituição da República Federativa do Brasil - CRFB dispõe sobre o direito fundamental de todos ao meio ambiente ecologicamente equilibrado, essencial à sadia qualidade de vida, incumbido ao Poder Público e à coletividade o dever de defesa e preservação (Art. 225), elege a proteção do meio ambiente como um 
princípio da ordem econômica, quando dispõe que a ordem econômica, fundada na valorização do trabalho humano e na livre iniciativa, tem por fim assegurar a todos a existência digna, conforme os ditames da justiça social (Art. 170, VI).

A CRFB também regulamenta os princípios da informação e participação popular como direitos fundamentais essenciais para Estado democrático, que devem ser compreendidos como acesso à informação qualificada e participação efetiva no processo de elaboração e execução de políticas públicas. O poder público tem o dever de propiciar a participação popular e todas as informações necessárias e para que os cidadãos participem do processo decisório adequadamente.

O princípio da participação é reconhecido pelos doutrinadores do direito ambiental e tem fundamento o artigo 10 da Declaração do Rio sobre Meio Ambiente e Desenvolvimento (Rio 92).

A melhor maneira de tratar as questões ambientais é assegurar a participação, no nível apropriado, de todos os cidadãos interessados. No nível nacional, cada indivíduo terá acesso adequado às informações relativas ao meio ambiente de que disponham as autoridades públicas, inclusive informações acerca de materiais e atividades perigosas em suas comunidades, bem como a oportunidade de participar dos processos decisórios. Os Estados irão facilitar e estimular a conscientização e a participação popular, colocando as informações à disposição de todos. Será proporcionado o acesso efetivo a mecanismos judiciais e administrativos, inclusive no que se refere à compensação e reparação de danos. (PARANÁ, s.d, s.p.)

Michel Prieur (2015, s.p.) alerta que uma gestão durável do meio ambiente implica no envolvimento da população (os grupos de interesse sociais, econômicos, culturais, Organizações não Governamentais - ONGs) no processo de reflexão, planejamento e decisão, tanto por medidas gerais, como pelas decisões particulares capazes de afetar o meio ambiente.

No Brasil, a participação da cidadania vai se configurar nas práticas dos movimentos organizados, das entidades civis e na participação ativa dos cidadãos, mobilizados através de fóruns e espaços públicos diferenciados (JACOBI, BARBI, 
2007).

A participação da população é essencial para o enfrentamento das questões ambientais, possibilitando a análise das diretrizes e obstáculos, a partir da perspectiva da comunidade. Todavia, Jacobi e Barbi (2007, p. 3) destacam que essa é uma realidade distante:

\begin{abstract}
Entretanto, ainda não incorporaram os grupos sociais normalmente excluídos dos mecanismos tradicionais de deliberação como atores com presença nos processos decisórios. Isto decorre do fato que estes grupos ainda não possuem os recursos econômicos e sociais e as informações que permitiriam sua participação nas atividades que permeiam processos decisórios em torno de questões ambientais.
\end{abstract}

Apesar destas dificuldades, é importante compreender, como ressalta Silva e Pedra (2016, s.p.), que a democracia não está vinculada apenas à limitação de poder para assegurar as liberdades individuais, mas também à participação da população no processo de tomada de decisões

Neste sentido, para que ocorra a formação de uma sociedade ativa é necessário a busca por novas formas de administração do poder político, onde sejam fortalecidas a atuação dos indivíduos, a partir da transparência dos procedimentos públicos.

O fortalecimento da participação vai se dar a partir dos princípios da informação e participação ambiental, que caminham juntos e determinantes para a concretização de uma atuação eficaz.

$\mathrm{O}$ artigo $225, \S 1^{\circ}, \mathrm{IV}$, da $\mathrm{CRFB}$ assegura o direito ao meio ambiente ecologicamente equilibrado e atribui ao poder público o dever exigir um estudo prévio de impacto ambiental, em se tratando de atividade, potencialmente, causadora de degradação ao meio ambiente, com a obrigação de dar publicidade ao estudo.

É importante que seja publicado o Relatório de Impacto Ambiental - RIMA, referente ao estudo prévio de impacto ambiental, pois a população deve ter acesso a essa informação imprescindível para que esteja informada e possa participar 
ativamente das decisões no âmbito ambiental.

A informação possibilita a manifestação qualificada, portanto, à medida que as informações são recebidas pelos órgãos ambientais, devem ser disponibilizadas para a sociedade civil. O conhecimento ambiental deve ser transmitido de forma a possibilitar tempo suficiente aos informados para influenciarem efetivamente na tomada de decisão, construção das políticas públicas, ou para recorrer ao poder judiciário para garantir proteção ao fundamental ao meio ambiente equilibrado.

Esta atuação pode ocorrer de forma individual ou coletiva, por meio da representação das comunidades, associações ou Organizações não governamentais ONGS, em espaços como conselhos ambientais, nas audiências públicas, no procedimento de estudo de impacto ambiental e nas ações judiciais.

O Estudo de Impacto ambiental e o RIMA vão subsidiar a realização também das audiências públicas, que são essenciais para concretizar a participação da população na gestão ambiental, principalmente se determinada obra ou atividade gerar impactos no modo de vida da comunidade.

Com a promulgação da Constituição da República de 1988, percebeu-se de forma nítida a intenção do legislador de conferir destaque à proteção ambiental, de modo a exigir o Estudo prévio de Impacto Ambiental como antecedente lógico e obrigatório para a instalação de obra ou atividades causadoras se significativo risco ao meio ambiente (SILVA; PEDRA, 2016, s.p.).

A resolução $n^{\circ}$ 009/87 do Conselho Nacional do Meio Ambiente CONAMA, disciplina a realização de audiências públicas, nos processos de licenciamento ambiental. A resolução exige que, durante a sua realização, deve ser exposto aos interessados o RIMA, contendo a descrição da atividade ou obra, os impactos ambientais, sociais, culturais e econômicos para que a população possa fazer contribuir com as críticas e sugestões e influenciar a decisão do gestor.

Como ressalta Silva e Pedra: "Assim, quem melhor do que a própria comunidade diretamente relacionada e envolvida com resultado a ser obtido pela 
atividade potencialmente causadora de dano ambiental para deliberar[...]" (SILVA; PEDRA, 2016, s.p.). Em virtude disso, a atuação da população na gestão ambiental concorre para o exercício pleno da cidadania, não cabendo, uma transferência de informação posterior ao acontecimento de uma tragédia, ela deve ser prévia. Para Silva e Pedra (2016, p. 18): “Torna-se fundamental que a sociedade receba informações prévias e úteis sobre a mera possibilidade de risco ambiental, não sendo coerente fazê-lo apenas depois de ultimado o dano".

Os Conselhos de Meio Ambiente também são espaços de participação, na medida em que possuem representantes da sociedade civil na sua composição. Entretanto, é essencial que haja representação paritária entre representantes do setor público e dos vários atores da sociedade civil, visando decisões comprometidas com o interesse e garantia dos direitos da comunidade diretamente impactada pelo projeto ou política pública. Nos conselhos são observadas, muitas vezes, resultados desiguais e não satisfatórios para a população em geral, em virtude das diferenças regionais, e algumas decisões acabam por serem decididas pela presença majoritária do representante governamental, podendo aumentar o poder da representação de resultados (JACOBI; BARBI, 2007, s.p.).

Por conseguinte, a atuação popular é indispensável para a concretização das políticas públicas ambientais, de forma eficaz, e que correspondam a realidade das suas regiões, já que de nada adianta criar uma política que não seja útil para a comunidade no entorno.

Além da informação, a educação ambiental também é determinante neste processo de participação. A educação promove o engajamento dos sujeitos na questão ambiental e em outras questões responsáveis pela sua sadia qualidade de vida. É primordial compreender a relação entre a comunidade e o meio ambiente, considerando os aspectos sociais, econômicos e políticos, como observa Loureiro e Cunha: 
Nesta, parte-se de um princípio de grande relevância para a construção do processo democrático e autônomo da gestão ambiental: os sujeitos são entendidos como indivíduos historicamente determinados, construídos e construindo socialmente em uma ação política com vistas a transformação societária (LOUREIRO; CUNHA, 2008, s.p.).

A educação aliada da informação, pode promover a atuação adequada da população, concretizando um espaço democrático de cidadania popular. É interessante analisar a dimensão da participação sobre o viés de teorias da democracia, e dentre elas a da democracia participativa de Jean Jaques Rousseau.

\section{A CONTRIBUIÇÃO DA DEMOCRACIA PARTICIPATIVA DE ROUSSEAU}

O termo democracia vai designar o poder do povo, como esclarece Simone Goyard-Fabre (2003, p. 45): "Mas o tempo marcou-o com tantas determinações que aos poucos foi se adensando com uma sobrecarga semântica". De qualquer modo, no registro político enfatiza a autora, está seu núcleo semântico original e a esse respeito, se a democracia pode ser definida como o poder do povo, as democracias que hoje conhecemos são compostas de regimes que a vontade do povo é a fonte desse poder.

Todavia, as democracias de épocas passadas eram exercidas diretamente e as de hoje são exercidas por meio da mediação, como ressalta Goyard-Fabre (2003, p. 46): "as democracias atuais necessitam da mediação de representantes. Ainda assim, em toda a democracia, o "povo" é o motor principal do modo de governo". Sabendo que o povo é o detentor do poder, vale analisar os modelos de democracia participativa e deliberativa.

Para Frank Cunningham em teorias da democracia (2009, s.p.). A democracia participativa seria justamente o oposto da democracia representativa, pois, para esta última, a política é representativamente ativa a partir do domínio do governo e de grupos de interesse. Diferentemente, a democracia participativa considera a apatia ou 
desinteresse como uma falha, considerando que sua tarefa seria maximizar o engajamento ativo do cidadão. A democracia representativa vai se distinguir da deliberativa, também, em virtude do esgotamento dos meios institucionais e políticos:

Em face disto é que a democracia participativa ganha espaço e se desenvolve já como contrapondo da democracia representativa exatamente em face do esgotamento de suas possibilidades institucionais e políticas. $\mathrm{O}$ problema é que também há déficits na matriz participativa no que diz com a forma, quantidade e qualidade da participação, haja vista os níveis de cooptação ideológica, burocrática e econômica dos atores participantes em relação a interesses mais privados do que públicos (LEAL, 2013).

Apesar do espaço que a democracia representativa alcança, há um deficit no seu procedimento, que vai ser complementado pela teoria representativa, apesar do seu contrapondo.

Ademais, a democracia deliberativa e a participação objetivam dar efetividade de uma atuação social bem como a ampliação e abertura dos processos de decisão públicos a todos.

De acordo com Cunningham (2009, p. 36): “[...] para os democratas participativos a representação e a votação competitiva em eleições formais são vistas, no melhor dos casos, como males necessários[...]". Destarte, é importante haver a competitividade nas eleições formais para se buscar decisões harmoniosas, porém, a pretensão é substitui-las por decisões formadas por consensos.

Os democratas participativos, buscam a solidariedade, como sua virtude principal, ou seja, durante a tomada de decisões coletivas, devem ser encontrados objetivos mútuos e comuns entre os indivíduos, ao passo que a partir deste entendimento, nasce noções de compreensão e preocupação com todos os indivíduos.

Rousseau (1999, s.p.) já se preocupava com a liberdade e a força de cada homem, em como eles poderiam empregá-las sem se prejudicarem e negligenciarem os seus cuidados necessários. A partir disso, o autor busca uma forma de associação em que as pessoas estejam unidas umas às outras e, ao mesmo tempo, proteja e 
defenda cada uma delas de forma individual.

Esta forma de associação vai se dar a partir de um contrato formado por cláusulas analisadas por Rousseau (1999, p. 21): “essas cláusulas bem compreendidas se reduzem a uma só, a saber, a alienação total de cada associado, com todos os seus direitos, em favor de toda a comunidade". Desse modo, todos se entregam por completo, sendo uma condição igual, não sendo oneroso mais para alguns do que para outros.

\begin{abstract}
Além disso, verificando-se a alienação sem reserva, a união é tão perfeita quanto possa ser e nenhum associado nada mais tem a reclamar: porque, se alguns direitos restassem aos particulares, como não haveria nenhum superior comum que pudesse decidir entre eles e o público, por ser cada um, em algum ponto, seu próprio juiz, pretenderia em breve sê-lo em tudo, o estado natural subsistiria, e a associação se tornaria necessariamente tirânica ou vã (ROUSSEAU, 1999, p. 21).
\end{abstract}

A partir dessa premissa, como cada indivíduo passa a atuar coletivamente e não haverá uma pessoa associada que não tenha adquirido o mesmo direito que the foi concedido. Isso faz com que se ganhe maior força para conservar também o que se tem.

A partir daí, este ato de associação produz um conjunto moral e coletivo, que será composto por tantos membros quanto a assembleia de vozes e que vai receber a sua unidade desse mesmo ato, com o seu eu comum, com sua vida e sua vontade.

Rousseau analisa a relação entre associados e a Autoridade:

Essa pessoa pública assim formada da união de todas as outras tomava outrora o nome de cidade, e assume atualmente o de república ou de corpo político, que é chamado por seus membros Estado, quando é passivo, soberano, quando ativo. Autoridade, quando comparado aos seus semelhantes. Em relação aos associados, tomam coletivamente o nome e povo, e se denominam em particular cidadãos como participes da autoridade soberana e, súditos, quando sujeitos às leis do Estado (ROUSSEAU, 1999, p. 22).

Dessa maneira, o corpo político vai adquirir a vontade geral, que encarna um 
imperativo moral para as pessoas promoverem interesses comuns e não apenas particulares, ao mesmo tempo, quando se atribui poder a esse corpo, os indivíduos experimentam a preservação de seus interesses, passando a estarem ligados uns aos outros na busca pelo bem comum.

Christiana Ochoa (2008) ensina sobre o argumento de autoridade: "The origin $f$ the theory of participatory democracy is often credited to jean-jacques Rousseau who presented the argument that authority over a people can only be legitimate if it leaves those who it governs as free they were prior to their submitting to that authority". ${ }^{4}$

Para Rousseau (1999, s.p.), democracia se refere a uma composição possível de um executivo, onde o povo inteiro ou sua maioria executa as leis tão bem quanto as constrói, ou seja, a população funcionaria como órgão legislativo. Desse modo, quanto maior o Estado, menor seria a democracia.

Alguns críticos afirmam que pela teoria de Rousseau seriam deixadas sementes do totalitarismo, pois quando as pessoas abrissem mão de sua liberdade, isto não ocorreria de forma espontânea; ao contrário, ocorreria contra a sua vontade, como ressalta Cunningham (2009, p. 37): "Em particular, essa concepção é declarada como especialmente suscetível ao perigo proporcionado pelo 'espaço vazio` da democracia, descrito no capítulo 2. Os críticos se aproveitam de uma tese central de Rousseau de que alguém pode ser "forçado a ser livre"'.

Isto ocorre porque, como afirma Rousseau (1999, p. 25), “[...] Aquele que se recusar a obedecer à vontade geral a isso será constrangido por todo o corpo". Esta afirmação de Rousseau é interpretada pelos críticos como semente de totalitarismo em virtude de ele concordar com o constrangimento para que se pudesse obedecer à vontade geral. Como ressaltam Pereira e Fonseca (2018, p. 10), existe um paradoxo,

\footnotetext{
4 Tradução livre da autora: "A origem da teoria da democracia participativa é frequentemente oferecida por Jean-Jacques Rousseau, que apresentou o argumento de que a autoridade sobre um povo só pode ser legítima se deixar aqueles que governa como livres antes de se submeterem àquela autoridade". (OCHOA, 2008).
} 
pois é negada a liberdade de buscar seus interesses particulares, mas há a intensificação da sua liberdade como cidadão.

É válido ressaltar que a democracia participativa difere de uma compreensão sexista de Rousseau, onde ele defende que as mulheres existem apenas para servir aos homens, sendo sua teoria aproveitada parcialmente pelo participacionismo, excluindo as questões problemáticas de interpretação. Como explica Cunningham (2009, p. 37): "Por isso, Carole Pateman, uma feminista e uma das principais representantes da teoria participativo-democrática, pode apelar à parte central de sua teoria, ao mesmo tempo em que se considera o seu sexismo uma aberração". Neste viés, se democratas participativos são atraídos por pontos de vista de Rousseau, isso se dá em virtude de interpretarem sua teoria de modo útil aos seus fins.

Apesar das críticas trazidas, continuando na interpretação da teoria de Rousseau, dentro de uma perspectiva participativo-democrática, é interessante interpretar que a democracia como o controle dos indivíduos pelos seus próprios objetivos e interesses, podendo inclusive virem a instruir os governos a realizar os desejos dessas pessoas.

Para Cunningham (2009, p. 38): "Essa perspectiva conota uma relação de continuidade entre pessoas e governo que é quebrada quando este é visto como um representante". Neste sentido, quando o governo é visto dessa maneira, está a um passo dele se tornar um corpo com seus próprios interesses, adquirindo poderes estatais e passando a negociar com esses indivíduos ou realizar contratos. Quando essa continuidade é quebrada, o governo passa a distorcer a sua função de executar a vontade do corpo do governo, passando a ser independente e com poderes especiais, ameaçando a concretização dos interesses da população, que são afastados para concretizar interesses políticos do governo.

É evidente a prevalência do contrato e da vontade geral, que é a necessidade pela busca do interesse comum, diferente da vontade de todos, que está direcionada aos interesses privados de cada pessoa, vindo a ser uma soma de vontade destes, por 
isso a vontade geral não pode ser interpretada como aquilo que todas as pessoas poderiam votar a favor (PEREIRA; FONSECA, 2018, s.p.).

A vontade geral é a vontade da maioria que somente pode ser alcançada quando os cidadãos usam seus votos para expressar opiniões se a proposta está de acordo com essa vontade da maioria. Alerta Cunningham (2009, p. 39): "Nem pode a vontade geral simplesmente ser aquilo sobre o que há acordo unânime, visto que isso pode ser obtido pelas pessoas visando somente a interesses privados, mas conduzindo a um resultado comum $[\ldots]$ "..

Por conseguinte, a vontade geral não pode ser traduzida por meio de concordâncias, consensos, acordos, ela é a opinião da maioria, mas esta deve acontecer de modo que suas atitudes objetivem o bem comum proposto pela vontade geral; ela não pode ser traduzida nessas formas, pois pode ocorrer um aproveitamento do meio em busca de interesses privados.

No capítulo 4 foi observado que, conquanto nem todos os democratas liberais vejam a agregação de interesses como o objetivo da democracia, há um elemento inescapável de agregação na teoria liberal-democrática: de acordo com o pluralismo, supõe-se que as pessoas votem sob a base de interesses antecedentes e geralmente diversos, a mistura dos quais determinará a distribuição dos votos (CUNNINGHAM, 2009, p. 39).

Cunningham (2009, s.p.) ressalta que para Rousseau esses resultados demonstram, justamente, como não se trata mais da vontade de todos, pois as pessoas votam de acordo com suas preferências, não agem de acordo com a vontade geral, as obrigando a determinar o que o bem comum requer quando votam.

Para Rousseau as pessoas que buscam tomar decisões com base na vontade geral, devem respeitar os princípios: “[..]o homem, que até então não levara em conta então a si mesmo, se viu obrigado a agir com base em outros princípios e a consultar sua razão antes de ouvir seus pendores" (ROUSSEAU, 1999, p. 25).

A tomada de decisão coletiva democrática para Cunningham (2009, p. 39): "[...] é, portanto, exatamente este comprometer-se a encontrar e a promover o bem 
público. Na forma tal tomada de decisão é mais bem vista como um esforço na construção de um consenso, em vez de uma disputa entre os votantes". Se forem vistos como uma disputa, os procedimentos democráticos se tornam regras de um jogo que cada um deseja vencer.

É interessante ressaltar que a vontade geral tenderia para a igualdade e que, portanto, a busca pelo bem comum seria entender que poderia beneficiar igualmente a todos: "Uma objeção que vem prontamente a cabeça é que pode haver várias alternativas, de tal forma que é ainda necessário para os que deliberam de forma associada singularizar uma delas" (CUNNINGHAM, 2009, p. 40). Rousseau também preza pela Igualdade:

Em vez de destruir a igualdade natural, o pacto fundamental substitui, ao contrário, por uma igualdade moral e legítima aquilo que a natureza poderia trazer de desigualdade física entre os homens, e podendo ser desiguais em força ou talento, todos se tornam iguais por convenção e de direito (ROUSSEAU, 1999, p. 30).

Outra questão é relação entre a disponibilidade de recursos e a igualdade. Em razão de conflitos de interesses, decorrentes da escassez de recursos, poderia não ser encontrado o bem comum e, assim, a igualdade substantiva não seria possível. Porém, para os democratas participativos, esse problema seria um resultado da insuficiência de sentimentos comunitários de compromisso com o bem comum.

Para Rousseau (1999, s.p.), a escassez seria uma questão de má distribuição de recursos, o que prejudicaria a busca pela igualdade, bem como a atuação de todos na busca pelo bem comum. Neste contexto, a democracia deliberativa com maximização dessa participação qualificada, pode ser analisada especificamente no direito ambiental.

\section{A APLICAÇÃO DO PARTICIPACIONISMO E DA DELIBERAÇÃO NA MAXIMIZAÇÃO DO DEBATE SOCIOAMBIENTAL}


Uma questão relevante a ser analisada diz respeito a criação de formas e estímulos para que ocorra a participação popular na construção de políticas públicas de impacto socioambiental. Para que esta participação seja qualificada, deve contribuir efetivamente para deliberação por meio de estratégias criadas a partir do pressuposto do participacionismo.

$\mathrm{Na}$ democracia participativa, estado e sociedade civil não são entidades diferentes, ou seja, não existe nada que possa dividir um estado que governa e os seus cidadãos que são governados, baseado no argumento de Rousseau da existência de apenas um contrato que cria o corpo político (CUNNINGHAM, 2009, s.p.).

Para Cunningham a respeito desse corpo político do governo formal: "Os participacionistas tipicamente consideram a acusação de estatismo mais plausível em abstrato do que em concreto. Sua preocupação principal é que a democracia seja promovida fora do governo formal em todas as instituições da sociedade civil" (CUNNINGHAM, 2009, p. 38).

$\mathrm{Na}$ busca de maior atuação popular, o alvo dos participacionistas começou pelas universidades:

\begin{abstract}
Mantendo-se com a declaração de Port Huron, um alvo principal de atenção para os primeiros participacionistas foram as universidades, sobre as quais os estudantes radicais insistiram e algumas vezes asseguraram uma democratização parcial, envolvendo estudantes na tomada de decisão no nível das aulas, bem como em comitês e coisas semelhantes como políticas curriculares e de graduação (CUNNINGHAM, 2009, s.p.).
\end{abstract}

Os estudantes buscavam seus espaços de debates e diálogos, bem como estarem presentes atuando em todas as suas atividades. Os democratas participativos defendiam modos de democratizar locais de trabalho, famílias e relações humanas com o meio ambiente. Todas essas são decisões que envolvem o Estado, mas que podem ser sujeitos a democratização.

Algumas críticas começaram a nascer a respeito da não participação das 
pessoas neste debate. Cunningham alerta que "A reação participacionista a crítica de que poucas pessoas estão interessadas em devotar tempo a conselhos nos locais de trabalho ou comitês de vizinhança ilumina um segundo grupo de recomendações pertinentes ao tópico corrente" (CUNNINGHAM, 2009, p. 38).

Ocorre que o participacionismo estava sofrendo críticas de que as pessoas não se sentiam motivadas e interessadas a participar de debates, pois não queriam gastar seu tempo nessas atividades, e isso se dava, muitas vezes, por não existir a cultura de resolver questões sociais através de diálogos.

Isso pode decorrer da inefetividade e indisponibilidade dos próprios fóruns. Eles poderiam não ser vistos como verdadeiros meios de mudanças e soluções, mas como atividades ineficazes e que poderiam não trazer verdadeiras mudanças.

Cunningham explica que essa apatia decorre da ausência de poder. Ou seja, não é a apatia que gera a ausência de poder. A apatia decorre de uma atuação parcial e não qualificada. Essa questão é compreendida melhor quando analisamos o exemplo de uma democracia na indústria, na qual o administrador da empresa consultaria os trabalhadores sobre algumas questões pertinentes, mas sem dar a devida atenção a participação destes (CUNNINGHAM, 2009, s.p.). Certamente, teria efeito diferente se o administrador consultasse seus empregados, considerando seriamente suas ideias, para que cada membro individual de um corpo de tomada de decisão tivesse igual poder para determinar o resultado dessas decisões, informando para eles que a sua presença poderia alterar a decisão e sua ausência faria a diferença.

A apatia ainda pode existir mesmo havendo oportunidades de atuação plena para os trabalhadores, visto que não é suficiente ser disponibilizado espaços de diálogo, se tal presença não fizer uma efetiva diferença no processo de decisão.

A democracia é apropriada quando soluções alternativas a situações problemáticas estão disponíveis; contudo, a tomada de decisão democrática é de valor limitado quando problemas ou soluções alternativas são definidos por pessoas diferentes daquelas que se presume que devam tratar delas e/ou quando há um pequeno controle sobre como ou se soluções aceitas serão implantadas (CUNNINGHAM, 2009, p. 39). 
A atuação plena vai requerer o envolvimento dos cidadãos em todos os estágios de tomada de decisão. Excluir da tomada de decisão pessoas que lidam com os problemas a serem debatidos enfraquecerá tanto a participação, como o entusiasmo de participar.

Outro componente relevante que complementa e garante a qualidade do participacionismo é a deliberação.

A democracia deliberativa é analisada por Cunningham (2009) que interpreta os ensinamentos deixados por Habermas (1979), considerado por muitos autores como o pai filosófico da teoria deliberativa, buscando defender instituições legítimas que seriam baseadas na concordância da participação dos indivíduos no procedimento democrático, contribuindo para o discurso (CUNNINGHAM, 2009, s.p.).

A ideia da deliberação é a busca por decisões coletivas cada vez mais legítimas e racionais, ou seja, que cheguem a soluções verdadeiramente efetivas na vida da população, e para que isso seja alcançado, o debate vai além de apenas se criar possibilidades e espaços de atuação.

A democracia deliberativa vai justamente complementar a participativa, como esclarece Cunningham:

Admitindo variações, todos atualmente nesta popular escola da teoria democrática poderiam concordar que essas formulações articulam o coração da democracia deliberativa. A posição contrária- algumas vezes identificada pelos democratas deliberativos como "liberal" e algumas vezes como a teoria da escolha social- descreve os cidadãos como entrando no processo político democrático com preferências fixas que eles visam promover pelo uso das instituições e regras democráticas (CUNNINGHAM, 2009, p. 47).

A questão das preferências fixas seria um dos motivos da necessidade de se buscar um melhor aperfeiçoamento e concretização da teoria da democrática participativa. Cunningham afirma que "Essas instituições e regras funcionam para agregar preferências diferentes dos cidadãos, sendo legítimas quando as pessoas ao 
menos tacitamente consentem em serem obrigadas por elas" (CUNNINGHAM, 2009, p. 47).

Apenas a democracia participativa não é suficiente para o democrata deliberativo, pois não basta que as pessoas concordem com o procedimento democrático, tendo em vista que, estas podem aderir à participação por inúmeros motivos e interesses.

Os processos democráticos passam a ser legítimos quando encorajam a deliberação de questões específicas sobre as regras que formam o debate, bem como, sobre a maneira como serão aplicadas. O que vai garantir a legitimidade dessa deliberação e também ao seu resultado, é a capacitação e liberdade de argumentação e debate nos fóruns, como ensina Cunningham: “[...] os participantes têm de ser aptos para livre e igualitariamente chegarem a preferências informadas e adquirirem e exercitarem as habilidades requeridas para a participação efetiva nos fóruns" (CUNNINGHAM, 2009, p. 47).

Cunningham alerta que sobre a possibilidade desentendimentos podem ser superada por procedimentos que garantam imparcialidade: "Confrontados com o desentendimento, os cidadãos podem se submeter a um procedimento imparcial, como votar, e ter esperança de que suas preferências irão vencer o debate, ou eles podem barganhar reciprocamente para chegar a um resultado negociado que seja aceitável" (CUNNINGHAM, 2009, p. 47).

No procedimento, as pessoas entram no debate sem expectativa de que suas preferências vão mudar durante os processos, ou seja, participam do debate com "preconceitos" e ideias já existentes que não se alteram ao final.

Se pessoas ao entrarem no debate, para decidir questões pertinentes a toda a comunidade sem abrir mão das expectativas que possuem sobre determinados fatos e ideias, as soluções fixadas ao final deste debate não serão eficazes para a coletividade, e interesses individuais determinarão as decisões a serem tomadas.

Essas reflexões auxiliam a adotar a melhor forma de promover a participação 
da população na gestão ambiental e certamente os Conselhos ambientais podem atender a esse objetivo:

Por suas características, muitos atores sociais percebem nos conselhos um potencial democrático e reformador. Verdadeiros canais de comunicação entre sociedade e Estado, com ampliação do espaço público e participação cidadã efetiva. Espaços que abrem um precedente para o acesso à discussão que pode ir além da opinião, conforme o formato do conselho- deliberação ou normatização- podendo ter implicações diretas nas decisões políticas que afetam a vida dos membros de uma dada comunidade (ALCANTARA, 2010, p. 7).

Os conselhos são espaços para que os atores sociais ganhem oportunidades para ter voz ativa e possam participar de decisões de impactos socioambientais. Alcantara ensina que "novos interesses são explicitados e inseridos no complexo jogo das decisões políticas que, à medida que são transparecidos pelo discurso argumentativo expondo a legitimidade das demandas, não podem ser 'simplesmente' excluídos" (ALCANTARA, 2010, p. 7).

Tendo em vista que as políticas ambientais podem interferir na vida dos indivíduos e em virtude da necessidade de chamar atenção para a proteção ambiental, é essencial a participação dessas pessoas nesses conselhos.

Perscrutando a realidade brasileira, onde as desigualdades são características marcantes da sociedade, promover entendimentos e convergências, ou ao menos o respeito nas demandas entre os interesses de grupos díspares, não é uma tarefa fácil. Tradicionalmente um conflito de interesses se resolve na imposição da vontade daquele que possui melhores condições econômicas, em última instância através da força bruta, ainda que por meio de ações ilegítimas do Estado que atende, muitas vezes, a interesses escusos (ALCANTARA, 2010, p. 7).

A implementação de uma gestão ambiental compartilhada, através de espaços públicos possibilita a cooperação de uma diversidade de atores, com a possibilidade de se decidir questões de responsabilidade solidária, coletiva e democrática. Os conselhos também viabilizam decisões baseadas em suporte técnico necessário para 
alcançar a melhor decisão., como destacado por Alcantara (2010, p. 7):

Considerando a estrutura desses conselhos é possível afirmar que os mesmos proporcionam, no exercício de uma dada atividade que ali será analisada, a utilização de técnicas de apropriação e modificação dos elementos naturais cientificamente mais criteriosas, com relação à eficiência e sustentabilidade, dado a necessidade de suporte técnico multidisciplinar na implementação e funcionamento desses espaços.

Vai ocorrer nestes debates a inserção de sentidos extra tecnológicos, considerando nas discussões aspectos socioambientais, como a proteção da biodiversidade e dos povos e comunidades tradicionais, e não apenas a perspectiva de crescimento econômico. Lima também ressalta que é em virtude das novas demandas da sociedade que surge a necessidade de novos modelos de gestão: "Las nuevas demandas de la sociedad actual han forzado el estado a "modernizarse" y desarrollar nuevos modelos de gestión que posibiliten um mejor trato de los bienes públicos y sus interesses" (LIMA, 2009, p. 3).

A participação no debate ambiental não costuma ser satisfatória, em função da dimensão política que envolve a formação dos Conselhos, como esclarece Alcantara: "Um dos pilares mais frágeis e que sustenta a operacionalidade dos conselhos de uma forma geral, reside na dimensão subjetiva dos fenômenos políticos, ou seja, na cultura política da sociedade e na sua tradição participativa" (ALCANTARA, 2010, p. 8).

Isto decorre, muitas vezes, em virtude da falta de engajamento da população nas decisões que envolvem impactos socioambientais. Em muitos casos, são criadas oportunidades de debates, porém ainda assim não ocorre uma atuação satisfatória, ou seja, não é suficiente a existência de espaços de debate, é preciso que haja mecanismos de estímulo para a participação efetiva, como a informação e a educação ambiental.

A teoria da democracia participativa auxilia na compreensão da necessidade de que a população reconheça e acredite que sua atuação pode fazer diferença no 
debate e que ela pode contribuir para a concretização de melhores políticas. Para tanto, é imprescindível a atribuição de poder na participação para que influencie efetivamente na decisão final e afaste a apatia.

Neste aspecto, é interessante o complemento da teoria deliberativa na participativa, pois mesmo que existam oportunidades de participar, as pessoas vão para o debate com pressupostos já direcionados, como as preferências fixas que Cunningham ressalta. Desse modo, para que ao final seja concretizada uma atuação de qualidade, é importante que todos possam renunciar a tais preferências e cheguem a conclusões satisfatórias para todos.

Um exemplo dessas preferências fixas é o que acontece quando estamos diante de debates, entre críticos que defendem um desenvolvimento sustentável e outros que priorizam um crescimento econômico, a qualquer custo. As pessoas não renunciam as suas ideias ao debaterem sobre a melhor saída para o meio ambiente, $o$ que pode comprometer a decisão, ocasionando uma escolha que pode não ser a melhor para o meio ambiente ecologicamente equilibrado.

Posto isso, resta demonstrada a necessidade de deixar de lado preferências existentes para se obter a participação qualificada e, consequentemente, uma decisão racional e eficiente.

Pode-se concluir que a deliberação e a participação podem auxiliar na melhor interpretação sobre como o debate na questão ambiental deve ocorrer, garantindo uma participação qualificada, visto que a mera existência de espaços de debates não é suficiente. É preciso atentar ainda para uma atuação que deixe de lado preconceitos já existentes.

\section{CONSIDERAÇÕES FINAIS}

A participação popular no debate ambiental é imprescindível, tendo em vista o risco de impactos socioambientais, gerados por atividades ou obras, que 
podem comprometer a saúde, a condição econômica, cultural ou mesmo alterar todo o modo de vida da população e comprometer a viabilidade do meio ambiente para as gerações futuras.

Os princípios da informação e da participação ambiental exigem a atuação popular na construção de políticas públicas de impacto socioambiental, para que a população possa atuar na defesa do meio ambiente ecologicamente equilibrado. Os princípios são complementares, na medida em que a informação prévia e adequada é essencial para a participação qualificada e efetiva.

A teoria da democracia participativa auxilia na interpretação e fortalecimento da participação, demonstrando que não é suficiente a criação de espaços de participação, pois muitas vezes, a população não é estimulada a participar mesmo em questões que interessam a todos, como as questões relacionadas ao meio ambiente.

É preciso que seja atribuído poder a essa atuação, ou seja, que os indivíduos saibam que sua presença pode fazer diferença e influenciar na decisão final, e que sua atuação não será contrariada, mas sim levada em consideração a cada contribuição feita.

Por conseguinte, a democracia deliberativa complementa o participacionismo, de modo que é importante não apenas que seja dado poder nos espaços de atuação, mais ainda, que todos estejam aptos para deliberar sobre as questões ambientais e renunciem aos seus preconceitos.

Dessa forma, se as pessoas estiverem comprometidas com seus preconceitos nos locais de debates, eles vão influenciar na tomada de decisão, que será baseada em seus interesses privados, não sendo possível chegar em uma decisão qualificada para todos.

As teorias da democracia participativa e deliberativa juntas, podem contribuir para uma maximização da participação da população nas questões ambientais, já que podem auxiliar na melhor interpretação e garantia de como deve ocorrer uma participação de qualidade, trazendo bons resultados para o desenvolvimento 
sustentável, a conservação dos recursos naturais e mitigação dos impactos socioambientais para a população.

\section{REFERÊNCIAS FINAIS}

ALCANTARA, Leonardo Alejandro Comide. Poder, território e participação social: Uma reflexão acerca dos espaços de deliberação coletiva no sistema brasileiro de gestão Ambiental. Trabalho Publicado nos Anais do XIX Encontro Nacional do Conpedi-Fortaleza, $2010 . \quad$ Disponível: http://www.publicadireito.com.br/conpedi/manaus/arquivos/anais/fortaleza/4145.pd f. Acesso em 19/09/2019.

BRASIL. Palácio do Planalto. Presidência da República. Constituição da República Federativa do Brasil, de 05 de outubro de 1988. Disponível em: http://www.planalto.gov.br/ccivil_03/constituicao/constituicaocompilado.htm. Acesso em: 15 jul. 2019.

CONAMA, Ministério do Meio Ambiente. Resolução no 9, de 03 de dezembro de 1987.

CUNNINGHAM, Frank. Teorias da Democracia: uma introdução Crítica. Porto Alegre: Artmed, 2009.

EMMANOUILIDIS, Bruna; MAAS, Rosana Helena. Os contornos do acesso à informação nos modelos de democracia participativa e democracia deliberativa. In: XV Seminário Internacional Demandas Sociais e Políticas Públicas na Sociedade Contemporânea e XI Mostra Internacional de Trabalhos Científicos, 2018, Santa Cruz do Sul. XV Seminário Internacional Demandas Sociais e Políticas Públicas na Sociedade Contemporânea, 2018. v. XV. Disponível em: http://online.unisc.br/acadnet/anais/index.php/sidspp/article/view/18765. Acesso em: 19/09/2019.

GOYARD-FABRE, Simone. O que é democracia? A genealogia filosófica de uma grande aventura humana. São Paulo: editora Martins Fontes, 2003.

JACOBI, Pedro. Governança Institucional de problemas Ambientais. Revista Política e Sociedade, $\mathrm{n}^{\mathrm{o}}$ 07, out, 2005. Disponível em: https://periodicos.ufsc.br/index.php/politica/article/view/1969. Acesso em: 19/09/2019. 
JACOBI; Pedro Roberto; BARBI, Fabiana. Democracia e participação na gestão dos recursos hídricos no Brasil. Revista Katál, v. 10, Jul/Dez, 2007. Disponível em: < http://www.scielo.br/pdf/rk/v10n2/a12v10n2> Acesso em: 19/09/2019.

LEAL, Rogério Gesta. Qual democracia: a necessidade premente de romper com a univocidade identitária artificial e casuística do fenômeno político. Revista do Direito, Santa Cruz do Sul, n. ${ }^{\circ}$ 39, p. 03 a 17, jan-jul. 2013. Disponível em: file:///C:/Users/carol/Downloads/2688-15289-1-PB\%20(1).pdf. Acesso em 19/09/2019.

LIMA, Luciano Barbosa de. Gestión y evaluación de participativa de políticas públicas: el caso de los presupoestos participativos. Brazilian Journal of International Law, Vol. 6, Issue 2 (July/December 2009), pp. 251-264. Disponível em: https://www.publicacoesacademicas.uniceub.br/prisma/article/view/862. Acesso em: 19/09/2019

LOUREIRO, Carlos Frederico Bernardo; CUNHA, Cláudia Conceição. Educação Ambiental e Gestão Participativa de Unidades de Conservação: Elementos para se pensar a Sustentabilidade Democrática. Revista Ambiente e Sociedade, $\mathrm{Jul} / \mathrm{Dez}$ 2008. Disponível em: http://www.scielo.br/scielo.php?pid=S1414753X2008000200003\&script=sci_abstra ct\&tlng=pt. Acesso em: 19/09/2019

OCHOA, Christiana. The Relationship of Participatory Democracy to Participatory Law Formation. Indiana Journal of Global Legal Studies, Vol. 15, Issue 1 (Winter 2008), pp. 5-18.

PARANÁ (Estado). Secretaria do Meio Ambiente e Recursos Hídricos. Declaração do Rio sobre Meio Ambiente e Desenvolvimento (Rio 92). Disponível em: http://www.meioambiente.pr.gov.br/arquivos/File/agenda21/Declaracao_Rio_Meio _Ambiente_Desenvolvimento.pdf. Acesso em: 27 jul. 2018.

PEREIRA, Carla Maria Peixoto; FONSECA, Luciana. "E que é a cidade, se não for o povo": Contribuições do modelo de democracia participativa para a concretização do direito à cidade. Revista de Direito Urbanístico, cidade e Alteridade, Porto Alegre, Jul/Dez, 2018. Disponível em: https://index.pkp.sfu.ca/index.php/record/view/984703. Acesso em: 19/09/2019.

PRIEUR, Michel. Droit de l'environment droit durable. 2. ed. Bruxellles: Bruylant, 2015.

ROUSSEAU, Jean-Jacques. O contrato social. Princípios do Direito Político. 
Tradução de Antônio de Pádua Danesi. São Paulo: Martins Fontes, 1999.

SILVA, Rodrigo Monteiro da; PEDRA, Adriano Sant'Ana. Transparência nas audiências públicas ambientais como instrumento de maximização ao dever fundamental de proteção ao meio ambiente. Revista Brasileira de estudos políticos, $\mathrm{n}^{\mathrm{o}} 112$, Jan/Jun, 2016. Disponível em: https://pos.direito.ufmg.br/rbep/index.php/rbep/article/view/P.00347191.2016V112P271. Acesso em: 19/09/2019.

Data da submissão: $12 / 11 / 2020$ Data da primeira avaliação: 13/12/2020 Data da segunda avaliação:01/04/2021 Data da aprovação: 01/04/2021 